\title{
Faktor-Faktor yang Mempengaruhi Ketaatan Minum Obat pada Penyakit Kronik
}

\author{
Maula Al Farisi \\ Pendidikan Dokter, Fakultas Kedokteran, Universitas Lampung \\ Correspondence email: maulaalfarisii07@gmail.com
}

\begin{abstract}
Abstrak. Kepatuhan adalah faktor kunci yang terkait dengan efektivitas semua terapi farmakologis. Ketidakpatuhan pengobatan adalah penghalang yang signifikan untuk mencapai hasil kesehatan yang positif terutama untuk pasien yang menderita penyakit kronis. Meningkatkan kepatuhan minum obat adalah prioritas kesehatan masyarakat dan dapat mengurangi beban ekonomi dan kesehatan. Tujuan dari penelitian ini adalah untuk menilai kepatuhan pengobatan terhadap beberapa penyakit kronis yang umum. Ada banyak tantangan dalam memahami alasan ketidakpatuhan. Komponen utama dalam pengelolaan pasien dengan masalah kesehatan kronis adalah penilaian kepatuhannya terhadap rejimen terapeutik. Tingkat kepatuhan pasien yang rendah dengan efektivitas terapi telah dikaitkan dengan peningkatan risiko kesehatan yang merugikan, peningkatan pengeluaran perawatan kesehatan melalui rumah sakit dan perawatan rumah sakit, kualitas hidup yang lebih rendah, dan tingkat yang lebih tinggi dari kematian Dalam penelitian ini kepatuhan pengobatan pada penyakit kronis ditemukan suboptimal dan dikaitkan dengan karakteristik sosio-demografi pasien. Intervensi yang disesuaikan dengan pasien diperlukan untuk mencapai kepatuhan yang cukup terhadap rejimen obat terapeutik. Hasil yang baik dari penyakit kronis sangat tergantung pada tingkat kepatuhan pasien terhadap pengobatan. Banyak penelitian telah menunjukkan bahwa beberapa tingkat ketidakpatuhan terjadi secara universal, di negara-negara kaya dan miskin, dan bahkan terlihat pada penyakit yang mengancam jiwa.
\end{abstract}

Kata kunci : faktor, ketaatan pengobatan, penyakit kronik

\begin{abstract}
Adherence is a key factor related to the effectiveness of all pharmacological therapies. Non-compliance with treatment is a significant barrier to achieving positive health outcomes especially for patients suffering from chronic diseases. Improving medication adherence is a public health priority and can reduce the economic and health burden. The purpose of this study is to assess treatment compliance with several common chronic diseases. There are many challenges in understanding the reasons for non-compliance. The main component in the management of patients with chronic health problems is the assessment of their adherence to therapeutic regimens. Low levels of patient adherence to therapeutic effectiveness have been associated with increased adverse health risks, increased spending on health care through hospitals and hospital care, lower quality of life, and higher rates of death. In this study treatment adherence to chronic diseases found suboptimal and is associated with sociodemographic characteristics of patients. Patient-adjusted interventions are needed to achieve adequate adherence to therapeutic drug regimens. The good outcome of chronic illness depends greatly on the level of patient compliance with treatment. Many studies have shown that some degree of non-compliance occurs universally, in rich and poor countries, and is even seen in lifethreatening diseases.
\end{abstract}

Keywords : factors, treatment obedience, chronic disease

\section{PENDAHULUAN}

Lebih dari setengah orang dewasa berusia 18 dan lebih tua memiliki setidaknya satu kondisi kronis; lebih dari seperempat memiliki setidaknya dua. Delapan puluh enam persen dari pengeluaran perawatan kesehatan nasional \$ 2,7 triliun pada tahun 2014 adalah atas nama orang-orang dengan penyakit kronis dan kondisi kesehatan mental. Tujuh dari sepuluh penyebab kematian terkait dengan penyakit kronis termasuk penyakit jantung, kanker, penyakit pernapasan kronis, stroke, Alzheimer, diabetes, dan penyakit hati kronis.

Kepatuhan terhadap minum obat pada penyakit kronis telah menjadi perhatian para peneliti selama beberapa dekade. Merupakan langkah penting dalam keberhasilan terapi obat dan tantangan utama bagi para tenaga kesehatan. Dengan meningkatnya jumlah perawatan mandiri yang efektif, kebutuhan jelas untuk pemahaman dan manajemen ketidakpatuhan yang lebih baik. Kepatuhan memiliki banyak definisi tetapi esensi tetap sama di setiap pernyataan yaitu "sejauh mana pasien tetap dengan rekomendasi dari profesional perawatan kesehatan" (V.N., I.I., D.G., \& A.S., 2017).

\section{METODE PENELITIAN}

Penelitian ini merupakan studi literature review, di mana peneliti mencari, menggabungkan inti sari serta menganalisis fakta dari beberapasumber ilmiah yang akurat dan valid, yang mendukung dan menjadi bukti. Studi literatur menyajikan ulang materi yang diterbitkan sebelumnya, dan melaporkan fakta atau analisis baru. Tinjauan literatur memberikan ringkasan berupa publikasi terbaik dan paling relevan. kemudian membandingkan hasil yang disajikan dalam makalah 


\section{HASIL DAN PEMBAHASAN}

Kepatuhan dalam minum obat adalah langkah penting dalam pengobatan penyakit, dan inkonsistensi pasien terhadap rejimen dapat mengakibatkan kondisi kesehatan yang buruk, peningkatan biaya perawatan, dan waktu pemulihan yang lama. Ketidakpatuhan telah diakui sebagai masalah kesehatan masyarakat di negara maju dan berkembang. Selain itu, orang Afrika dan Asia ditemukan lebih tidak patuh dengan rejimen pengobatan (Abegaz, Shehab, Gebreyohannes, Bhagavathula, \& Elnour, 2017).

Karena alasan yang berbeda, pasien mungkin memutuskan untuk tidak mengambil obat yang diresepkan untuk mereka, serta menggunakan obat secara berlebihan dan tidak sesuai dosis. Jenis ketidakpatuhan utama yang memperlambat pemulihan, meskipun dapat dikurangi sampai batas tertentu dengan menggunakan teknologi dalam resep, sangat umum di daerah pedesaan di negara berkembang (Khera et al., 2016). Faktor-faktor seperti pendidikan, jenis kelamin, dan kedekatan dan frekuensi kunjungan ke fasilitas layanan kesehatan telah diidentifikasi bertanggung jawab atas perilaku tidak patuh terhadap resep elektronik di negara-negara miskin (Hudelson \& Cluver, 2015).

Kepatuhan terhadap penggunaan obat didefinisikan sebagai proporsi dosis obat yang diresepkan yang benar-benar dikonsumsi oleh pasien selama periode waktu tertentu. Istilah "Kepatuhan", menyiratkan peran aktif dalam kolaborasi dengan seorang resep, dan "ketidakpatuhan" mencakup beragam alasan bagi pasien yang tidak mengikuti rekomendasi perawatan (Brown \& Bussell, 2011). Kepatuhan adalah fenomena multidimensi yang ditentukan oleh interaksi lima set faktor, disebut "dimensi" oleh WHO (Lam \& Fresco, 2015).

Sosial / ekonomi: Orang yang mendapat dukungan sosial dari keluarga, teman, atau pengasuh untuk membantu rejimen pengobatan memiliki kepatuhan yang lebih baik terhadap pengobatan. Lingkungan hidup yang tidak stabil, akses terbatas ke perawatan kesehatan, kurangnya sumber daya keuangan, biaya pengobatan, dan jadwal kerja yang membebani telah dikaitkan dengan penurunan tingkat kepatuhan(Cutler, FernandezLlimos, Frommer, Benrimoj, \& Garcia-Cardenas, 2018).

Sistem perawatan kesehatan: Hubungan pasien dengan dokter adalah salah satu faktor terkait sistem perawatan kesehatan yang paling penting yang mempengaruhi kepatuhan. Hubungan yang baik antara pasien dan penyedia layanan kesehatan, yang memiliki dorongan dan penguatan dari penyedia layanan, memiliki dampak positif pada kepatuhan. Kurangnya komunikasi mengenai manfaat, petunjuk penggunaan, dan efek samping obat-obatan juga dapat berkontribusi terhadap ketidakpatuhan, terutama pada orang tua dengan masalah ingatan(Stavropoulou, 2011).

Terkait kondisi: Pemberian obat jangka panjang untuk banyak penyakit kronis dan kepatuhan terhadap rejimen sering menurun secara signifikan dari waktu ke waktu. Sering terjadi ketika pasien memiliki sedikit atau tidak ada gejala dan tidak adanya penghalang bagi orang untuk minum obat. Penting bagi pasien untuk memahami penyakit dan apa yang akan terjadi jika tidak diobati (Mishra, Gioia, Childress, Barnet, \& Webster, 2011).

Terkait dengan terapi: Kompleksitas rejimen obat, yang meliputi jumlah obat dan jumlah dosis harian yang diperlukan; durasi terapi; terapi yang tidak nyaman atau mengganggu gaya hidup dan efek samping seseorang telah dikaitkan dengan penurunan kepatuhan (Scanlon \& Vreeman, 2013).

Kepatuhan pengobatan adalah perilaku kompleks yang dipengaruhi oleh faktor-faktor di sepanjang rangkaian perawatan, yang berkaitan dengan pasien, penyedia, dan sistem kesehatan (Rolnick, Pawloski, Hedblom, Asche, \& Bruzek, 2013). Faktor yang berhubungan dengan pasien termasuk faktor yang tidak disengaja, yang sering memburuk dengan rejimen obat yang semakin kompleks (misalnya, lupa minum obat) atau atau tidak memahami dosis atau jadwal); dan faktor yang disengaja (mis., keputusan aktif untuk menghentikan atau memodifikasi rejimen pengobatan berdasarkan kemampuan untuk membayar, keyakinan dan sikap tentang penyakit mereka, efek samping obat, dan harapan untuk perbaikan)(Gadkari \& McHorney, 2012). Hambatan terkait pasien yaitu termasuk kurangnya keterlibatan dalam keputusan pengobatan, gangguan kognisi (mis., Terkait dengan penuaan atau penyakit), penyalahgunaan zat, depresi, dan kondisi kesehatan mental lainnya.

Faktor-faktor yang berhubungan dengan tenaga kesehatan termasuk hambatan untuk berkomunikasi dengan pasien dan pengasuhan, rejimen dosis yang kompleks, dan koordinasi perawatan yang terbatas di antara beberapa penyedia. Sistem perawatan kesehatan dan faktor-faktor pemberian layanan mencakup akses terbatas ke penyedia yang tepat untuk resep atau isi ulang, cakupan obat terlarang, biaya tinggi dan pembayaran, pelabelan dan instruksi obat yang tidak jelas, ketersediaan terbatas bahan pendidikan pasien yang sesuai dengan budaya, dan waktu penyedia yang tidak memadai untuk meninjau manfaat, risiko, dan alternatif untuk obat yang diresepkan.

Penyakit kronis merupakan penyakit yang bersifat berkepanjangan, tidak sembuh secara spontan, dan jarang sembuh total. Jenis paling umum adalah penyakit kardiovaskular (seperti hipertensi, penyakit arteri koroner, stroke dan gagal jantung), berbagai bentuk radang sendi, masalah pernapasan, termasuk asma dan penyakit paru obstruktif kronis, diabetes dan epilepsy (Marrero \& Adashi, 2015).

Beberapa dekade mendatang akan terlihat kelanjutan tren yang meningkat yang dihasilkan dari penurunan kesehatan yang dramatis (dan akibatnya populasi yang menua) yang terjadi secara bervariasi di beberapa negara selama beberapa dekade terakhir. 
Kombinasi populasi yang menua dan dengan peningkatan kebiasaan merokok dan perubahan gaya hidup lainnya berarti bahwa penyakit kronis akan semakin meningkat(Reda \& Biadgilign, 2012).

Alasan yang dilaporkan terhadap ketidakpatuhan terhadap rejimen pengobatan di Amerika Serikat pada tahun 2013, dapat dilihat pada gambar 1.

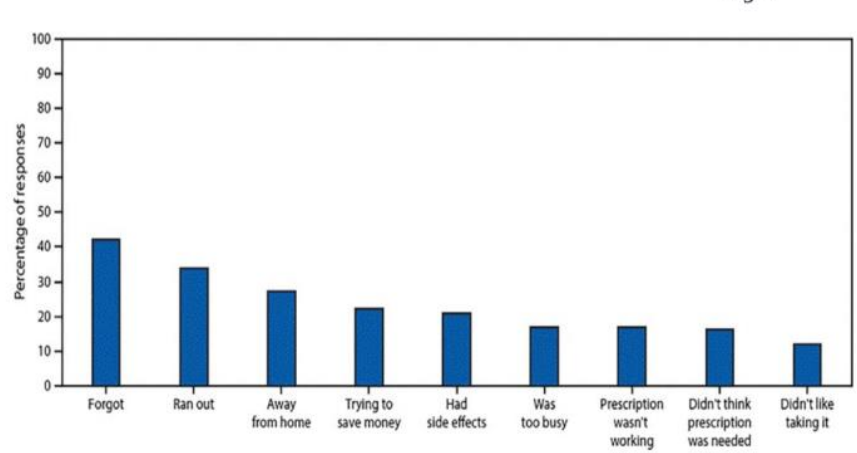

Gambar 1. Alasan yang dilaporkan karena ketidakpatuhan terhadap rejimen pengobatan yang direkomendasikan (Neiman et al., 2017).

Upaya yang berhasil untuk meningkatkan tingkat kepatuhan terhadap pengobatan dilakukan penggabungan beberapa strategi pada pelayanan kesehatan. Strategi yang terbukti hemat biaya untuk mengurangi ketidakpatuhan yang tidak disengaja adalah penggunaan kotak pil dan blister untuk mengatur rejimen obat dengan cara yang jelas dan sederhana (Ruppar, Delgado, \& Temple, 2015). Terdapat beberapa cara efektif untuk meningkatkan kepatuhan terhadap pengobatan, seperti monitor pil elektronik yang dapat mengingatkan pasien untuk meminum obat mereka dan memberikan pesan kepada penyedia layanan kesehatan ketika dosis obat terjadwal terlewatkan, mendukung peningkatan kepatuhan pengobatan (Checchi, Huybrechts, Avorn, \& Kesselheim, 2014).

Penelitian yang dilakukan Saleem et al terhadap 385 pasien, $236(61,3 \%)$ dari pasien memiliki pengetahuan rata-rata tentang hipertensi sementara 249 $(64,7 \%)$ dikategorikan memiliki pengetahuan yang buruk. Tidak ada pasien yang dianggap patuh dalam penelitian ini. Koefisien korelasi antara skor total pengetahuan dan kepatuhan total adalah 0,170 (p $<0,001$ ), menunjukkan hubungan terbalik antara skor pengetahuan dan tingkat kepatuhan. Dapat disimpulkan meskipun tingkat pengetahuan rata-rata, pasien tidak yakin tentang manfaat penggunaan obat terus menerus yang mengakibatkan ketidakpatuhan terhadap rejimen. Mendidik pasien tentang manfaat obat dan mengklarifikasi keraguan mengenai penggunaan obat menghasilkan kontrol hipertensi yang lebih baik (Saleem, Hassali, Shafie, Awad, \& Bashir, 2011).

Penelitian yang dilakukan terhadap 300 pasien dalam penelitian ini, 46,66\% pasien adalah laki-laki dan $53,33 \%$ perempuan. Usia rata-rata adalah 56,69 tahun mulai dari 24 hingga 90 tahun. $65 \%$ pasien tidak berpendidikan.40,00\% memakai satu obat, $53,33 \%$ dua hingga empat obat dan $6,66 \%$ lebih dari empat obat. $63,33 \%$ memiliki kepatuhan pengobatan yang rendah, $35,00 \%$ sedang dan hanya $1,66 \%$ memiliki kepatuhan yang tinggi. Dibandingkan dengan $14,28 \%$ pria, $43,75 \%$ wanita cukup patuh terhadap pengobatan. $41,02 \%$ pasien tidak berpendidikan memiliki kepatuhan sedang dibandingkan dengan $14,28 \%$ pasien berpendidikan. 92,30\% pasien muda memiliki kepatuhan rendah dibandingkan dengan $53,25 \%$ pada orang dewasa. $44,79 \%$ dari pasien yang menerima obat tunggal memiliki kepatuhan sedang dibandingkan dengan $25,00 \%$ pada mereka yang menerima beberapa obat. Analisis regresi linier menunjukkan bahwa tingkat kepatuhan pengobatan dikaitkan dengan jenis kelamin pasien, usia, tingkat pendidikan, dan jumlah obat yang diresepkan.(Mir, Muzamil, Bhat, Amin, \& Shakeel, 2018)

\section{SIMPULAN}

Kepatuhan pengobatan sangat penting untuk menurunkan komplikasi terhadap penyakit kronis dan mengurangi biaya perawatan kesehatan. Strategi yang berhasil untuk membuktikan kepatuhan pengobatan termasuk memastikan akses ke pelayanan kesehatan di seluruh rangkaian perawatan dan menerapkan perawatan berbasis tim; mendidik dan memberdayakan pasien untuk memahami rejimen pengobatan dan manfaatnya; mengurangi hambatan untuk mendapatkan pengobatan, termasuk pengurangan biaya dan upaya untuk mempertahankan atau melibatkan kembali pasien dalam perawatan; dan penggunaan alat teknologi informasi kesehatan untuk meningkatkan pengambilan keputusan dan komunikasi selama dan setelah kunjungan . Memahami akar penyebab ketidakpatuhan pengobatan dan pendekatan biaya yang terjangkau sangat penting untuk meningkatkan kepatuhan dan meningkatkan dampak kesehatan jangka panjang.

\section{DAFTAR PUSTAKA}

Abegaz, T. M., Shehab, A., Gebreyohannes, E. A., Bhagavathula, A. S., \& Elnour, A. A. (2017). Nonadherence to antihypertensive drugs a systematic review and meta-analysis. Medicine (United https://doi.org/10.1097/MD.0000000000005641

Brown, M. T., \& Bussell, J. K. (2011). Medication adherence: WHO cares? Mayo Clinic Proceedings. https://doi.org/10.4065/mcp.2010.0575

Checchi, K. D., Huybrechts, K. F., Avorn, J., \& Kesselheim, A. S. (2014). Electronic medication packaging devices and medication adherence: A systematic review. JAMA - Journal of the American Medical Association. https://doi.org/10.1001/jama.2014.10059

Cutler, R. L., Fernandez-Llimos, F., Frommer, M., 
Benrimoj, C., \& Garcia-Cardenas, V. (2018). Economic impact of medication non-adherence by disease groups: A systematic review. BMJ Open. https://doi.org/10.1136/bmjopen-2017-016982

Gadkari, A. S., \& McHorney, C. A. (2012). Unintentional non-adherence to chronic prescription medications: How unintentional is it really? BMC Health Services Research. https://doi.org/10.1186/1472-6963-12-98

Hudelson, C., \& Cluver, L. (2015). Factors associated with adherence to antiretroviral therapy among adolescents living with HIV/AIDS in low- and middle-income countries: A systematic review. AIDS Care - Psychological and Socio-Medical Aspects of

AIDS/HIV. https://doi.org/10.1080/09540121.2015.1011073

Khera, A. V., Emdin, C. A., Drake, I., Natarajan, P., Bick, A. G., Cook, N. R., ... Kathiresan, S. (2016). Genetic risk, adherence to a healthy lifestyle, and coronary disease. New England Journal of Medicine. https://doi.org/10.1056/NEJMoa1605086

Lam, W. Y., \& Fresco, P. (2015). Medication Adherence Measures: An Overview. BioMed Research International. https://doi.org/10.1155/2015/217047

Marrero, S., \& Adashi, E. Y. (2015). Noncommunicable diseases. Seminars in Reproductive Medicine. https://doi.org/10.1055/s-0034-1395277

Mir, S. A., Muzamil, F., Bhat, M. U. D., Amin, A., \& Shakeel, D. (2018). Assessment of medication adherence among patients with chronic diseases: a descriptive cross-sectional study. International Journal of Basic \& Clinical Pharmacology, 8(1), 115. https://doi.org/10.18203/2319 2003.ijbcp20185168

Mishra, S. I., Gioia, D., Childress, S., Barnet, B., \& Webster, R. L. (2011). Adherence to medication regimens among low-income patients with multiple comorbid chronic conditions. Health and Social Work. https://doi.org/10.1093/hsw/36.4.249

Neiman, A. B., Ruppar, T., Ho, M., Garber, L., Weidle, P. J., Hong, Y., ... Thorpe, P. G. (2017). CDC grand rounds: Improving medication adherence for chronic disease management - innovations and opportunities. Morbidity and Mortality Weekly Report. https://doi.org/10.15585/mmwr.mm6645a2

Reda, A. A., \& Biadgilign, S. (2012). Determinants of adherence to antiretroviral therapy among HIVinfected patients in Africa. AIDS Research and Treatment. https://doi.org/10.1155/2012/574656

Rolnick, S. J., Pawloski, P. A., Hedblom, B. D., Asche, S. E., \& Bruzek, R. J. (2013). Patient characteristics associated with medication adherence. Clinical Medicine and Research. https://doi.org/10.3121/cmr.2013.1113
Ruppar, T. M., Delgado, J. M., \& Temple, J. (2015). Medication adherence interventions for heart failure patients: A meta-analysis. European Journal of Cardiovascular Nursing. https://doi.org/10.1177/1474515115571213

Saleem, F., Hassali, M. A., Shafie, A. A., Awad, A. G., \& Bashir, S. (2011). Association between knowledge and drug adherence in patients with hypertension in Quetta, Pakistan. Tropical Journal of Pharmaceutical Research. https://doi.org/10.4314/tjpr.v10i2.66552

Scanlon, M. L., \& Vreeman, R. C. (2013). Current strategies for improving access and adherence to antiretroviral therapies in resource-limited settings. HIV/AIDS - Research and Palliative Care. https://doi.org/10.2147/HIV.S28912

Stavropoulou, C. (2011). Non-adherence to medication and doctor-patient relationship: Evidence from a European survey. Patient Education and Counseling. https://doi.org/10.1016/j.pec.2010.04.039

V.N., L., I.I., C., D.G., K., \& A.S., B. (2017). Factors affecting medication adherence trajectories for elderly outpatients with chronic heart failure. European Journal of Heart Failure. https://doi.org/10.1002/ejhf.833 